\title{
STRATEGI PELAKSANAAN KETENTUAN DUTY- FREE QUOTA-FREE INDONESIA DALAM KERANGKA ORGANISASI PERDAGANGAN DUNIA (WORLD TRADE ORGANIZATION)
}

\author{
Veri Antoni* \\ Departemen Hukum Bisnis, Fakultas Hukum Universitas Gadjah Mada \\ Jalan Sosio Justisia No. 1, Bulaksumur, Sleman, D.I. Yogyakarta 55281
}

\begin{abstract}
Ministerial Conference on Duty-Free Quota-Free (DFQF) in Hongkong, 2015, mandated for the developed countries to provide DFQF market access for at least 97 per cent of products originating from LDCs. For the developing countries shall seek to provide DFQF market access for products originating from LDCs. Indonesia was one of the developing countries that agreed in conference. The article aims to identify and analyze what strategy should be done by Indonesia related to the implementation of DFQF (duty free quota free) agreement. Indonesia as contracting parties of the establishment of WTO agreement should follow WTO's agreements including DFQF's agreement for the least development countries/LDCs). In granting DFQF preference to the LDCs countries, Indonesiashould use GSP (Generalized System of Preference) scheme or pattern because of the absence of clear regulation about DFQF. The implementation by making requirements that must be followed by the LDCs countries if they wish to obtain DFQF preferences as happened when a country wants to obtain GSP. The requirements can be related to DFQF products, criteria DFQF recipients, limitation DFQF value and suspension act, and the period of granting DFQF preference.
\end{abstract}

Keywords: world trade organization, duty free quota free, strategy.

\section{Intisari}

Pertemuan Konfrensi Tingkat Menteri (KTM) di Hongkong tahun 2005 terkait duty-free quota-free (DFQF) mengamanatkan negara-negara maju untuk memberikan fasilitas DFQF sebesar $97 \%$ dari jumlah pos tarifnya kepada negara kurang berkembang (least developed countries/LDCs). Untuk negara berkembang dianjurkan untuk memberikan hal tersebut. Indonesia adalah salah satu negara berkembang yang menyepakati konferensi tersebut. Tulisan bertujuan untuk mengetahui dan menganalisa strategi apa yang sebaiknya dilakukan oleh Indonesia terkait pelaksanaan DFQF terhadap negara kurang berkembang. Sebagai salah satu negara Organisasi Perdagangan Dunia (World Trade Organization/WTO), Indonesia terikat dengan perjanjian-perjanjian dalam kerangka perjanjian WTO, termasuk kesepakatan DFQF. Dalam pemberian preferensi DFQF ini, Indonesia sebaiknya menggunakan skema atau pola seperti Generalized System of Preference (GSP) mengingat tidak adanya pengaturan yang jelas terkait dengan DFQF. Penerapan DFQF dapat diwujudkan dengan membuat persyaratan-persyaratan yang harus diikuti oleh negara LDCs apabila mereka berkeinginan untuk memperoleh preferensi DFQF seperti suatu negara ketika berkeinginan memperoleh GSP. Persyaratan tersebut antara lain terkait dengan produk DFQF, kriteria negara penerima DFQF, batasan nilai DFQF dan pemberhentian sementara, dan jangka waktu pemberian preferensi DFQF. Kata kunci: world trade organization, duty free quota free, strategi.

\section{Pokok Muatan}

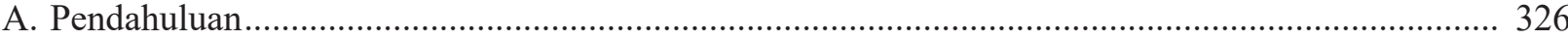

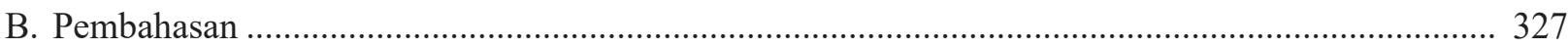

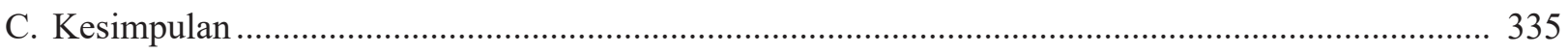

* Alamat korespondensi: antoni.veri@ugm.ac.id 


\section{A. Pendahuluan}

Perdagangan internasional merupakan aktivitas yang tidak dapat dihindari lagi oleh negaranegara di dunia. Terlebih lagi dalam era globalisasi ini perdagangan internasional menjadi kebutuhan yang penting bagi banyak negara. ${ }^{1}$ Perdagangan internasional diyakini telah memberikan manfaat besar bagi banyak negara. Praktik di beberapa negara bahkan menunjukkan bahwa perdagangan internasional sudah menjadi tulang punggung bagi suatu negara untuk menjadi makmur, sejahtera, dan kuat. $^{2}$

Hukum perdagangan internasional pada masa ini didasarkan pada perjanjian bilateral ataupun multilateral antarnegara, yang dimulai setelah berakhirnya Perang Dunia II. Pada tahun 1947, diadakan negosiasi untuk perjanjian internasional yang ditujukan untuk mengatur perdagangan barang, yang mana kesepakatan tersebut diwujudkan dalam GATT (General Agreement on Tarif and Trade). Pada tahun 1994 dibentuk wadah perdagangan internasional negara-negara dunia, yaitu World Trade Organization (WTO), meskipun inisiasi pembentukan organisasi perdagangan tersebut, telah dimulai sejak disepakati GATT di tahun 1947. ${ }^{3}$ Indonesia merupakan salah satu negara yang menjadi anggota WTO melalui UndangUndang Nomor 7 Tahun 1994 tentang Pengesahan Agreement Establishing WTO.

Negara berkembang (developing countries) dan LDCs mendapat perhatian khusus dalam WTO. Hal tersebut tidak mengherankan mengingat hampir 3/4 (tiga per empat) dari anggota WTO yang berjumlah 164 negara berasal dari negara berkembang. ${ }^{4}$ Lebih jauh, diperkirakan terdapat 145 ketentuan Peraturan Khusus dan Berbeda yang tersebar dalam persetujuan-persetujuan WTO, 107 di antaranya diadopsi pada Putaran Uruguay, dan 22 lainnya ditujukan khusus untuk LDCs. Di antara negara-negara yang dikategorikan sebagai LDCs menurut United Nations Conference On Trade And Development (UNCTAD), yang melakukan kegiatan perdagangan dengan Indonesia antara lain Angola, Benin, Burkina Faso, Burundi, Central African Republic, Chad, Democratic Republic of The Congo, Guinea, Haiti, Malawi, Madagascar, Malawi, Mali, Sinegal, Sierra Leone, Somalia, South Sudan, Uganda, Zambia, Bhutan, Timor Leste, Vanuatu, dan lain-lain. ${ }^{5}$

Peraturan Khusus dan Berbeda tersebut oleh Sekretariat WTO dikelompokkan atas pertama, ketentuan-ketentuan yang ditujukan untuk meningkatkan kesempatan berdagang bagi negara-negara berkembang; kedua, ketentuan yang mengharuskan para anggota WTO menjaga kepentingan anggota negara-negara berkembangnya; ketiga, fleksibilitas komitmen, tindakan, dan pemanfaatan kebijakan-kebijakan; keempat, periode masa transisi; kelima, bantuan teknis; dan keenam, ketentuan-ketentuan terkait dengan LDC's. ${ }^{6}$

Meskipun telah ada ketentuan Perlakuan Khusus dan Berbeda tersebut, sebagian besar negara-negara berkembang apalagi kurang berkembang, masih berkutat pada masalah-masalah kemiskinan dan belum memperoleh dampak positif akan keberadaan WTO. Kebanyakan dari mereka hanyalah konsumen dalam perdagangan dunia, mengingat produknya yang tidak mampu bersaing dalam pasar global. Oleh karenanya, sampai saat ini, negara berkembang terus berjuang agar produknya dapat bersaing, yang salah satunya adalah melalui pemberian tarif preferensi. Isu pemberian tarif preferensi kepada negara-negara LDCs untuk 
meningkatkan partisipasimereka dalamperdagangan internasional sudah sejak lama menjadi bagian dalam sistem perdagangan internasional. Konsep pemberian preferensi ini awalnya diberikan dalam bentuk Generalized System of Preference (GSP) yang diadopsi di New Delhi, India tahun 1968. Namun demikian, inisiatif preferensi perdagangan tersebut tidak sepenuhnya memberikan manfaat kepada LDCs. Oleh karenanya, kelompok LDCs terus melakukan negosiasi untuk DFQF Market Access, yang harus mencakup seluruh produk yang berasal dari LDCs. Di tahun 2005 keluarlah mandat Hongkong Ministerial Decision mengenai DFQF, yang intinya mewajibkan negara-negara maju untuk memberikan fasilitas DFQF sebesar 97\% dari jumlah pos tarifnya kepada LDCs. Sementara itu, untuk negara berkembang dianjurkan untuk memberikan hal tersebut.

Sejak diadopsinya Hongkong Ministerial Decision, telah banyak negara maju dan beberapa negara berkembang memberikan fasilitas DFQF, yang didasarkan persentase dari total pos tarif dari pada jumlah produk ekspor LDCs. Pada tahun 2012, misalnya, India memberlakukan DFQF sebesar 85\% dari total pos tarifnya, China sebesar $60 \%$, Korea Selatan sebesar 95\%, dan Taiwan sebesar 32\%. ${ }^{7}$

Mandat Hongkong Ministerial Decision ini kemudian dipertegas kembali dalam Bali Package yang merupakan hasil KTM IX WTO di Bali (Bali Ministerial Decision on Duty-Free Quota-Fee), tahun 2013. Berdasarkan Hongkong Ministerial Decision dan Bali Ministerial Decision, Indonesia sebagai negara berkembang kembali dianjurkan untuk memberikan fasilitas ini. Pada pertemuan G-20 di Seoul tahun 2011 Indonesia telah memberikan pernyataan untuk memberikan fasilitas DFQF kepada LDCs. Pada forum Trade Policy Review Indonesia tahun 2013 Indonesia juga kembali menyampaikan kesiapan Indonesia untuk mempertimbangkan pemberian fasilitas DFQF kepada LDCs. ${ }^{8}$

Bagi Indonesia, pemberian skema $\mathrm{DFQF}$ merupakan bentuk keberpihakan dan kepedulian terhadap peningkatan pembangunan ekonomi LDCs. Namun demikian, perlu dipahami juga bahwa pemberian fasilitas ini juga tidak boleh mencederai kepentingan nasional secara keseluruhan. Oleh karena itu, dalam rangka rencana pemberian DFQF, Indonesia perlu mengkaji beberapa hal di atas agar pemberian DFQF nantinya tidak merugikan kepentingan nasional Indonesia secara keseluruhan. Dalam rangka rencana pemberian DFQF tersebut, penulis tertarik untuk menulis terkait bagaimanakah strategi Indonesia untuk melaksanakannya agar tidak merugikan kepentingan nasional Indonesia dengan memberikan perbandingan penerapannya di negara-negara lain terlebih dahulu seperti Thailand, Tiongkok, dan India. Pertimbangan pemilihan Thailand karena sama dengan Indonesia sebagai anggota ASEAN (Association of Southeast Asian Nations), sedangkan Tiongkok dan India karena sama tergabung dengan Indonesia dalam Negara G20 (Group of Twenty) ${ }^{9}$ yang diperkirakan akan menjadi kekuatan baru ekonomi dunia.

\section{B. Pembahasan \\ 1. Perdagangan Dunia dan World Trade Organization.}

Dalam kegiatan perdagangan internasional tidak selalu dapat berjalan mulus seperti yang diharapkan. Tidak jarang menemui berbagai hambatan-hambatan, baik hambatan tarif (tariff barrier) maupun hambatan bukan tarif (non tariff barrier). Hambatan berupa tarif misalnya pengenaan pajak ataupun bea cukai terhadap produk perdagangan. Sementara itu, hambatan non tarif seperti penerapan undang-undang, peraturan, kebijakan atau praktik-praktik selain bea masuk

\footnotetext{
SwaOnline, "Indonesia Pertimbangkan DFQF untuk Negara Kurang Berkembang", https://swa.co.id/swa/trends/management/indonesiapertimbangkan-dfqf-untuk-negara-kurang-berkembang, diakses 3 Juli 2017.

"Indonesia Pertimbangkan DFQF untuk Negara Kurang Berkembang", Loc.cit.

G20 atau (Group of Twenty) adalah negara-negara mewakili dua per tiga populasi dunia, memproduksi $85 \%$ produk domestik bruto (PDB) dunia, dan menguasai $75 \%$ perdagangan dunia.
} 
impor yang menghambat perdagangan. ${ }^{10}$ Hambatan non tarif dapat berupa pemberlakuan persyaratan standar, misalnya standar mutu produk dari negara mitra dagang. ${ }^{11}$

Oleh karena itu, aktivitas perdagangan internasional yang semakin meningkat di era globalisasi tersebut, perlu untuk dikelola dengan tepat agar dapat mendatangkan kemanfaatan bagi semua pihak. ${ }^{12}$ Untuk mewujudkan hal tersebut, perdagangan internasional harus dilandasi dengan aturan main yang dapat dijadikan pedoman bagi negara-negara dalam pelaksanaan perdagangan internasional dengan negara mitra dagang. Aturan perdagangan internasional diperlukan karena empat alasan, yaitu (1) untuk mencegah digunakannya hambatan perdagangan terbatas menurut kepentingan suatu negara atau kelompok negara tertentu, (2) untuk memberikan tingkat keamanan dan keterdugaan dalam bertransaksi bagi pelaku usaha dan investor, (3) membantu pemerintah di setiap negara untuk menghadapi tantangan di era globalisasi ekonomi, dan (4) untuk mencapai penilaian yang lebih besar mengenai keadilan dalam hubungan ekonomi di era global. ${ }^{13}$

Hukum perdagangan internasional pada masa ini didasarkan pada perjanjian bilateral ataupun multilateral antarnegara, dimulai setelah berakhirnya Perang Dunia II. Pada tahun 1947, diadakan negosiasi untuk perjanjian internasional yang ditujukan untuk mengatur perdagangan barang, yang mana kesepakatan tersebut diwujudkan dalam GATT (General Agreement on Tariff and Trade). Namun demikian, pembentukan organisasinya baru terwujud di tahun 1994 melalui pendirian WTO. ${ }^{14}$

Sebagai organisasi internasional yang secara resmi mengatur perdagangan internasional, WTO menyediakan pengaturan secara global mengenai perdagangan internasional. Tujuan maupun struktur dari WTO tertuang dalam the Agreement Establishing of the WTO, yang juga dikenal dengan Marakesh Agreement, yang merupakan Final Act yang ditandatangani oleh signatories parties. WTO diberlakukan secara resmi pada tanggal 1 Januari 1995. WTO terbuka untuk masuknya negaranegara lain yang bukan contracting parties dalam GATT, tetapi ada ketentuan bahwa negara tersebut harus melakukan aksesi (accession) atau ratifikasi (ratification). Mukadimah atau Preamble of WTO Agreement mengindikasikan bahwa tujuan WTO adalah untuk membangun sistem perdagangan multilateral sesuai GATT, sebagaimana yang dihasilkan dalam Putaran Uruguay. Isu-isu yang dicakup dalam WTO Agreement tidak hanya mengenai liberalisasi perdagangan, akan tetapi juga meliputi standar kehidupan, ketenagakerjaan atau perburuhan, isu lingkungan, dan juga permasalahanpermasalahan negara-negara berkembang. ${ }^{15}$

\section{Amanat Hongkong Ministerial Decision dan Bali Ministerial Decision.}

Sebagaimana telah juga dijelaskan di awal bahwa DFQF berawal dari kesepakatan KTM (Konferensi Tingkat Menteri) di Hongkong. Berikut kesepakatan dalam KTM Hong Kong terkait pemberian fasilitas DFQF: ${ }^{16}$

"We agree that developed-country Members shall, and developing-country Members declaring themselves in a position to do so should:

a. (i). Provide duty-free and quota-free market access on a lasting basis, for all products originating from all LDCs by 2008 or no later than the start of the implementation period in

\footnotetext{
10 Paul Beynon, “Community Mutual Recognition Mutual Agreements, Technical Barriers to Trade, And the WTO Most Favoured Nation Principles", E.L.Rev. 2003, 28 (2), 231-249, hlm. 231

11 Eddy Herjanto (Kepala Puslitbang Standarisasi BSN), "Standarisasi: Peran Dan Perkembangannya Dalam Memfasilitasi Perdagangan Di Indonesia", 7 Mei 2008, hlm. 1.

12 Peter Van Den Bossche, 2005, The Law and Policy of the World Trade Organization-Text, Cases and Materials, Cambrige University Press, hlm. 35 .

Ibid. hlm. 36-37.

4 Michael Pryles, et. al., 2004, International Trade Law - Commentary and Materials, Thomson Reuter Legal, hlm. 684-685.

5 Ibid, hlm. 706.

16 "Ministerial Declaration: Annexes Adopted on 18 December 2005, Decision on Measures in Favour of Least-Developed Countries", https:// www.wto.org/english/thewto_e/minist_e/min05_e/final_annex_e.htm, pada 3 Juli 2017.
} 
a manner that ensures stability, security and predictability.

(ii) Members facing difficulties at this time to provide market access as set out above shall provide duty-free and quota-free market access for at least 97 per cent of products originating from LDCs, defined at the tariff line level, by 2008 or no later than the start of the implementation period. In addition, these Members shall take steps to progressively achieve compliance with the obligations set out above, taking into account the impact on other developing countries at similar levels of development, and, as appropriate, by incrementally building on the initial list of covered products.

(iii) Developing-country Members shall be permitted to phase in their commitments and shall enjoy appropriate flexibility in coverage.

$b$. Ensure that preferential rules of origin applicable to imports from LDCs are transparent and simple, and contribute to facilitating market access".

Sejak diadopsinya Hong Kong Decision, negara anggota WTO telah membuat kemajuan signifikan untuk dapat memberikan akses pasar DFQF terhadap produk yang berasal dari LDCs. Hampir semua negara maju telah memberikan akses pasar DFQF dan sejumlah negara berkembang juga telah memberikan hal serupa bagi produk LDCs. Dalam General Council Decision, tanggal 15 Juni 1999 on Waiver Prefential Tariff Treatment for LDCs, yang berlaku sampai tahun 2009, yang dalam salah satu klausulanya menyebutkan: ${ }^{17}$
"the provision of paragraph 1 of Article I of the GATT 1994 shall be waived until 30 June 2009, to the extent necessary to allow developing countries Members to provide preferential tariff treatment to product of least-developed countries, disignated as such by the United Natios, without being required to extend the same tariff rates to like products of any other Member,... on a generalized, non reciprocal, and non-discriminatory basis".

Kemudian, General Council Decision on Waiver Extention pada bulai Mei 2009 yang memperpanjang perlakuan pengaturan kepada negara berkembang untuk bisa memberikan preferensi tarif kepada LDCs tanpa harus memberikan perlakuan yang sama kepada negara anggota WTO lain. Pengabaian (waiver) ini berlaku sampai dengan tahun 2019. Dan terakhir, Bali Ministrial Decision on Duty Free Quota Free, tanggal 7 Desember 2013, yang dalam salah satu keputusannya menyebutkan: ${ }^{18}$

"Developing-country Members, declaring themselves in a position to do so, shall seek to provide duty - free and quota-free market access for products originating from LDCs, or shall seek to improve their existing duty-free and quota free coverage for such products, so as to provide increasingly greater market access to LDCs, prior to next Ministerial Conferences.

\section{Praktik Penerapan DFQF di Negara Lain.}

Sebelum membahas bagaimanakah strategi yang sebaiknya dilakukan oleh Indonesia terkait mandat DFQF, akan diberikan perkembangan pelaksanaan DFQF di negara-negara lain, yaitu Thailand, India, dan Tiongkok sebagai perbandingan.

a) Thailand

Skema DFQF di Thailand merupakan skema perlakuan istimewa non timbal balik kepada negara kurang berkembang, yang berbentuk perlakuan tarif preferensi berlaku sejak 9 April 2015 hingga 31 Desember 2020 terhadap semua negara yang dikategorikan oleh PBB (Perserikatan Bangsa-Bangsa) sebagai LDCs. Pemberian fasilitas bebas masuk dan bebas kuota dalam skema ini diperuntukkan bagi 6,998 produk pada sistem HS (Harmonized System) ${ }^{19} 8$ digit, atau mencakup 73,21 persen dari total tarrif

\footnotetext{
17 "Preferential Tariff Treatment For least-Developed Countries decision On Waive radopted On 15 June 1999", https://www.wto.org/english/ docs_e/legal_e/waiver1999_e.pdf, diakses 3 Juli 2017.

18 "Ministerial Conference ninth Session Bali, 3-6 December 2013 on Duty-Free And Quota-Free Market Access For Least-Developed Countries", https://www.wto.org/english/thewto_e/minist_e/mc9_e/bali_texts_combined_e.pdf, diakses 3 Juli 2019.
} 
lines Thailand. Produk ekspor LDCs yang masuk ke Thailand bisa memperoleh fasilitas tarif preferensi, namun produk tersebut harus memenuhi semua persyaratan sebagaimana tertuang dalam ketentuan Surat Keterangan (rules of origin) asal mengenai DFQF. ${ }^{20}$

Meski demikian, penerapan tarif preferensi terhadap produk ekspor dari LDCs dapat ditangguhkan sementara maupun permanen, apabila terdapat penipuan atau penyimpangan dari prosedur maupun peraturan terkait keterangan asal produk. Selain itu, jika perlakuan tarif preferensi menyebabkan produk yang diimpor dari LDCs melonjak tinggi sehingga menyebabkan kerugian maupun ancaman kerugian terhadap produk serupa dalam negeri, maka penerapan tarif preferensi ditangguhkan dan tarif normal untuk produk tersebut akan diberlakukan kembali. $^{21}$

b) Tiongkok

Di Tiongkok, skema DFQF untuk LDCs sudah diterapkan sejak 1 Juli 2010. Hingga saat ini, skema DFQF Tiongkok mencakup 60 persen tariflines dari total tarif line Tiongkok, dan akan terus menambah cakupan produk hingga 97 persen dari total tarif line-nya sesuai dengan kesepakatan negara anggota WTO pada Hongkong Ministerial Declaration. Skema DFQF Tiongkok dapat diakses oleh LDCs yang memiliki hubungan diplomatik dengan Tiongkok dalam rangka meningkatkan akses pasar bagi LDCs, sehingga lebih mampu bersaing dalam perdagangan internasional. Adapun cakupan produk LDCs yang diberikan fasilitas DFQF mencapai 4.788 pos tarif pada sistem HS 8 digit, misalnya kapas, kakao, biji logam langka, tembaga, nikel, kobal, alumnunium uranium titanium, logam mulia (perak), minyak mentah, gas alam cair, dan lain-lain. ${ }^{22}$

Hingga saat ini tercatat bahwa terdapat 40 LDCs yang telah diberikan skema DFQF ini, yaitu Ethiopia, Angola, Benin, Burundi, Equatorial Guinea, Eritrea, Djibouti, Kongo, Guinea, Guinea Bissau, Shao, Comoros, Liberia, Madagascar, Mali, Malawi, Mauritania, Mozambik, Rwanda, Sierra Leone, Senegal, Sudan, Tanzania, Togo, Uganda, Ceko, Zambia, Lesotho, Chad, Afrika Tengah, Afganistan, Timor-Leste, Maladewa, Bangladesh, Nepal, Samoa, Vanuatu, Yaman, Niger, dan Somalia. Selain itu, Tiongkok juga menawarkan preferential treatment hingga 90\% dari keseluruhan tariff line untuk ekspor dari Kamboja, Lao People's Democratic Republic, dan Myanmar di bawah China-ASEAN Free Trade Agreement, serta Lao PDR dan Bangladesh di bawah Asia Pacific Trade Agreement. ${ }^{23}$

Dalam rangka pelaksanaan skema ini, Custom Tariff Commision of State Council menjadi badan yang bertanggung jawab untuk mengeluarkan skema, dan Ministry of Finance, Ministry of Commerce, dan General Administration of Custom bertanggung jawab dalam hal pemberian persetujuan. Pemerintah Tiongkok juga mensyaratkan dokumen rules of origin dalam pemberian skema DFQF. Hal ini diatur berdasarkan surat keputusan General Administration of Custom Republik

19 Harmonized System atau biasa disebut HS adalah suatu daftar penggolongan barang yang dibuat secara sistematis dengan tujuan mempermudah penarifan, transaksi perdagangan, pengangkutan dan statistik yang telah diperbaiki dari sistem klasifikasi sebelumnya. Saat ini pengklasifikasian barang di Indonesia didasarkan kepada Harmonized System dan dituangkan ke dalam suatu daftar tarif yang disebut Buku Tarif Bea Mauk Indonesia (BTBMI). Lihat "Definisi dan Manfaat", http://djpen.kemendag.go.id/app_frontend/contents/147-definisi-manfaat, diakses 3 Agustus 2018 .

20 Tri Widodo, et.al., 2015, Analisis Rekomendasi Daftar Produk pemberian fasilitas Duty Free Quota Free (DFQF) bagi Produk Ekspor Negara Least Development Countries (LDCs), P2EB (Penelitian dan Pelatihan Ekonomi dan Bisnis, Fakultas Ekonomi, Universitas Gadjah Mada, Yogyakarta, hlm. 10-13.

Ibid.

Ibid.

Ibid. 
Rakyat Tiongkok Nomor 149 tanggal 31 Mei 2006 pada Annex IV tentang rule of origin untuk produk yang diberikan preferensi DFQF, yaitu: ${ }^{24}$

a) Produk yang seluruhnya didapat dari atau diproses di beneficiary country (negara penerima manfaat).

b) Produk yang sebagian didapat dari atau diproses di beneficiary country namun sudah melewati proses perubahan-perubahan yang bersifat substantif (substanstial transformation final) di negara tersebut.

b) India

Terkait dengan DFQF ini, India menggunakan skema yang disebut DFTP (Duty Free Tariff Preference Scheme). Skema ini merupakan preferensi tarif oleh Pemerintah India kepada negara kurang berkembang berupa duty free dan preferential market access. Rencana pemberian skema ini diumumkan oleh Perdana Menteri India sewaktu India-Africa Forum Summit pada tanggal 8 April 2008 di New Delhi dengan tujuan untuk memberikan preferensi tarif terhadap komoditi ekspor LDCs ke India. Secara resmi, skema ini mulai berjalan sejak 13 Agustus 2008 dengan cakupan produk mencapai $85 \%$ dari jumlah tarif line yang dimiliki India. ${ }^{25}$

Secara bertahap, applied custum duty juga akan dihilangkan selama 5 (lima) tahun dengan tingkat penurunan sebesar $20 \%$ setiap tahun. Selain itu, untuk positive list terdapat 9\% tariff line (458 produk) per Margin of Preference (MOP). Kisaran MOP tersebut adalah $10 \%-100 \%$ pada masing-masing jenis yang berbeda berdasarkan rate of duty untuk setiap tanggal importasi. Untuk exclusion list ${ }^{26}$, terdapat $6 \%$ tariff line (326 produk) dari jumlah tariff line yang tidak termasuk dalam skema duty free. Pemerintah India memberikan preferensi untuk produk-produk yang mereka sebut sebagai "particular interest to Africa", di antaranya kapas, kakao, alumunium, tembaga, gula tebu, pakaian, fillet ikan, dan berlian non-industri. Namun di saat yang sama, skema DFTP juga mengecualikan beberapa produk utama ekspor LDCs, yaitu kopi, teh, buah dan sayuran, rempah-rempah, besi, dan baja. ${ }^{27}$

Pada bulan April 2014, skema ini direvisi dan diperluas hingga $98 \%$ tarif line. Exclusion list juga telah berkurang secara signifikan. Jumlah tarif line untuk exclusion list berkurang dari 326 produk menjadi 97 produk saja. Sementara MOP List terbaru hanya memuat 114 tarif line dibandingkan dengan MOP List sebelumnya yang memuat 468 tarif line. Ini berarti bahwa 229 produk sudah dihapuskan dari exclusion list. Sebagian besar produk-produk ini sudah mendapatkan status duty free. Hanya beberapa produk seperti tomat, almond (shelled), dan walnut yang dipindahkan dari exclusion list ke positive list dengan MOP 25\%. Adapun beberapa produk yang sepenuhnya telah diliberalisasi adalah beras, jagung, hampir semua sayur dan buah-buahan (kecuali apel, dan bawang), dan sebagian besar waste and scrap metal (kecuali tembaga). Namun, skema baru ini tetap memasukkan beberapa produk yang merupakan ekspor utama LDCs, terutama LDCs Afrika, ke dalam exclusion list. Termasuk di dalamnya susu dan krim (dengan gula), kacang mete, kopi, teh, beberapa bumbu dan minyak sayur (misalnya biji rami dan wijen), tepung terigu, bir,

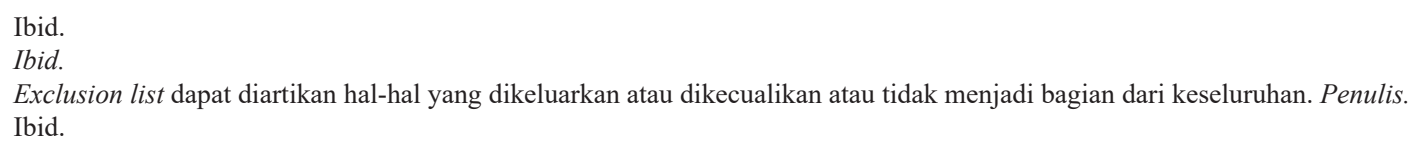


anggur, rokok dan tembakau, tembaga, dan produk lain terkait tembaga (misalnya bars, rods, cathodes, waste dan scrap) ${ }^{28}$

Skema DFTP sudah berlaku untuk 48 LDCs termasuk 33 negara LDCs di Afrika, yaitu Angola, Benin, Burkina Faso, Republik Afrika Tengah, Chad, Komoro, Kongo, Djibouti, Equatorial Guinea, Eritrea, Ethiopia, Guinea, Guinea Bissau, Gambia, Lesotho, Liberia, Madagascar, Malawi, Mali, Mauritania, Mozambique, Niger, Rwanda, Sao Tome\&Principe, Senegal, Sierra Leone, Somalia, Sudan, Togo, Uganda, Tanzania, Zambia, Afganistan, Bangladesh, Bhutan, Kamboja, Timor Timur, Kiribati, Lao PDR, Maldives, Myanmar, Nepal, Samoa, Solomon Island, Tuvalu, Vanuatu, Yaman, dan Haiti. Namun, dari 48 negara yang diberikan preferensi, hanya 29 LDCs yang sudah bergabung dalam skema ini dan 22 negara di antaranya merupakan negara di sub-Sahara Afrika. $^{29}$

Pemerintah India juga menerapkan preferential safeguard measure apabila terjadi peningkatan jumlah impor dari LDCs baik secara absolut ataupun secara relatif yang menyebabkan serious injury pada produksi dalam negeri India. Mekanisme ini akan dilakukan dengan pemberitahuan terlebih dahulu kepada negara penerima apabila India akan menerapkan safeguard duty, kecuali untuk keadaan yang mendesak dan produk pertanian. Selain itu, Pemerintah India juga mengatur tentang mekanisme pemberhentian skema DFTP kepada LDCs, jika: ${ }^{30}$

a. terdapat bukti-bukti yang menunjukkan terjadinya pelanggaran seperti penipuan dan pelanggaran lain termasuk tidak dipenuhinya syarat dalam pemberian skema DFQF termasuk dalam penerbitan dokumen rules of origin dan operational certification prosedures;

b. impor melebihi batas produksi yang bisa dilakukan dan kapasitas ekspor dari negara penerima; ;sepic. $\quad \mathrm{neg}$ a r a penerima telah lulus dari kriteria LDC dengan mengacu pada kriteria yang dikembangkan Pemerintah India.

d. Ketika negara penerima tidak lagi termasuk dalam golongan LDCs.

Mendasarkan pada tiga negara tersebut di atas tampak bahwa dalam pemberian DFQF ketiga negara tersebut memberikan persyaratan, adanya jangka tertentu—dalam arti untuk tidak selamanya, dan adanya batasan atau penghentian pemberian DFQF dalam kondisi tertentu, misalnya, terjadi lonjakan impor yang membahayakan negara pemberi $\mathrm{DFQF}$, dan lain sebagainya.

\section{Sikap dan Strategi Pelaksanaan Ketentuan DFQF bagi Indonesia}

Mencermati kesepakatan-kesepakatan tersebut di atas, sebagai salah satu negara yang telah meratifikasi perjanjian pendirian WTO, maka tentunya Indonesia haruslah mengikuti perjanjianperjanjian dalam kerangka perjanjian WTO, termasuk perjanjian DFQF sebagaimana tersebut di atas.

Namun demikian, mencermati putusan Hongkong Ministrial Decision tersebut di atas, tampak bahwa DFQF bersifat wajib untuk negaranegara maju. Hal ini tampak dari pengunaan frasa "developed-country Members shall", yang kemudian diikuti frasa "(i) provide duty free and quota free..". Sementara itu, untuk negara berkembang frasa yang digunakan adalah "developing-country Members declaring themselves in a position to do 
so should: (i) provide duty free and quota free...". Lebih jauh dalam Bali Ministrial Decision, frasa yang digunakan adalah, "Developing-country Members, declaring themselves in a position to do so, shall seek to provide duty - free and quota - free market". Pengunaan kata "should" dan "shall seek to provide", menandakan bahwa sifatnya adalah anjuran, bukan suatu kewajiban.

Meskipun bersifat anjuran dan bukan suatu keharusan, apabila dicermati perkembangan DFQF di negara lain, misalnya Thailand, India, dan Tiongkok yang telah menerapkan, sebagaimana tersebut di atas, maka DFQF bagi Indonesia juga patut untuk diterapkan. Apalagi, jika telah ada pernyataan Kepala Negara, Presiden Susilo Bambang Yudhoyono, dalam Konferensi Tingkat Menteri ke-9 WTO di Bali, Desember 2013, bahwa isu fasilitasi perdagangan serta kebijakan untuk negara kurang berkembang (LDC's) menjadi salah satu elemen penting di samping pertanian, fasilitasi perdagangan, dalam Bali Package (Paket Bali). ${ }^{31}$ Lebih dari itu, semangat DFQF adalah semangat membantu negara-negara yang masih terbelakang secara ekonomi dan secara moral ada kewajiban negara maju termasuk juga berkembang untuk membantu negara yang kurang mampu (masih terbelakang). Namun demikian, menjadi pertanyaan dalam hal Indonesia memang harus melaksanakan DFQF tersebut, bagaimanakah agar pelaksanaan DFQF tersebut tidak membawa kerugian pada Indonesia? M. Hawin, Guru Besar Fakultas Hukum, UGM, menyatakan pendapatnya bahwa dalam penerapan DFQF Indonesia sebaiknya mengunakan skema atau pola seperti GSP. ${ }^{32}$ Pendapat ini didasarkan bahwa tidak adanya pengaturan yang jelas terkait dengan DFQF. Pengaturan DFQF bersifat umum, antara lain, generality, non-reciprocity, non discrimination. Oleh karena itu, Indonesia dapat membuat tahapan komitmen yang fleksibel dalam cakupan (coverage), preferensi dalam rule of origin yang transparan, simpel, dan berkontribusi untuk memfasilitasi akses pasar, dan adanya kewajiban notifikasi terkait skema pelaksanaan pada Commitee on Trade and Development. ${ }^{33}$

Hal ini berbeda dengan pemberian skema GSP yang diberikan lebih detail. Lebih jauh, skema DFQF adalah juga bersifat unilateral (kesepakatan antara dua negara saja tanpa berakibat terhadap negara lain), yang juga sama dengan skema GSP. Ketiadaan pengaturan secara jelas dalam DFQF dapat menjadi alasan Indonesia untuk menerapkan skema (pola) GSP dalam pemberian DFQF. Yang diadopsi di sini adalah pola (skema) GSP, bukan ketentuan GSP-nya. Penerapan skema GSP adalah sejalan dengan ketentuan Pasal 87 Ayat (1) dan (2) Undang-Undang Nomor 7 Tahun 2014 tentang Perdagangan(selanjutnya disebut UU Perdagangan), yang menyatakan Pemerintah dapat memberikan preferensi perdagangan secara unilateral kepada negara kurang berkembang dengan tetap mengutamakan kepentingan nasional. Selanjutnya, ketentuan mengenai tata cara pemberian preferensi diatur dengan atau berdasarkan Peraturan Presiden. Akan tetapi, ketentuan Presiden sebagaimana dimaksud dalam ayat 2 tersebut sampai saat ini belum ada.

Ketentuan Pasal 87 Ayat (1) UU Perdagangan, yang menyatakan bahwa Pemerintah dapat memberikan preferensi perdagangan secara unilateral kepada negara kurang berkembang dengan tetap mengutamakan kepentingan nasional, merupakan landasan hukum pemberian DFQF oleh Indonesia. Namun, menjadi perhatian juga, dalam ketentuan sebagai Pasal 87 Ayat (1) UU Perdagangan tersebut, bahwa pemberian preferensi tersebut haruslah "mengutamakan kepentingan

\footnotetext{
31 Sekretariat BSN, "Konferensi Tingkat Menteri Ke 9 WTO, Bali Nusa Dua Convention Centre, 3-6 Desember 2013”, http://bsn.go.id/main/ berita/detail/4935/konferensi-tingkat-menteri-ke-9-wto-bali-nusa-dua-convention-centre-3-6-desember-2013\#.XRyBU_5S_IU, diakses 3 Juli 2019.

32 M. Hawin, Focus Group Discussion, “Analisis Rekomendasi Daftar Produk pemberian fasilitas Duty Free Quota Free (DFQF) bagi Produk Ekspor Negara Least Development Countries (LDCs), di Fakultas Ekonomi, Universitas Gadjah Mada, pada tanggal 5 November 2015.

33 "Handbook on Duty-Free Quata-Free and Rules Origin", United Nations Conference on Trade and Development, hlm 8.
} 
nasional".

Frasa "mengutamakan kepentingan nasional" diwujudkan dengan membuat persyaratanpersyarataan yang harus diikuiti dengan negara LDCs apabila mereka berkeinginan untuk memperoleh preferensi DFQF, seperti yang terjadi ketika suatu negara berkeinginan memperoleh GSP, maka negara pemberi GSP tersebut membebani calon negara-negara penerima dengan persyaratanpersyaratan. Dengan kata lain, pemberian DFQF bagi anggota LDC's, haruslah memenuhi persyaratanpersyaratan yang ditetapkan oleh pemerintah Indonesia. Tujuannya adalah untuk tetap menjaga kepentingan nasional Indonesia. Artinya, niat baik Indonesia memberikan DFQF tidak membawa kerugian bagi kepentingan Indonesia sendiri. Belajar dari pengalaman-pengalaman negara lain, termasuk yang memberikan GSP, persyaratanpersyaratan tersebut meliputi produk-produk yang diberikan preferensi DFQF dan persyaratanpersyaratan negara yang memperoleh $\mathrm{DFQF}$.

a) Persyaratan terkait produk DFQF Indonesia harus menentukan produkproduk apa saja yang akan dibuka untuk DFQF. Pembukaan produk untuk DFQF ini haruslah memperhatikan kepentingan Indonesia. Misalnya, produk tersebut tidak diproduksi di Indonesia sehingga tidak ada kompetisi antara produk dalam negeri dengan produk antoni DFQF. Atau bisa juga, produk yang dibebaskan tersebut, adalah produk-produk yang memang dibutuhkan oleh industri dalam negeri Indonesia.

b) Kriteria Negara Penerima DFQF.

Indonesia juga perlu membuat kriteriakriteria negara-negara yang dikecualikan untuk memperoleh fasilitas DFQF. Pengalaman-pengalaman dari negara lain dalam pemberian GSP misalnya, tidak akan diberikan fasilitas SP, apabila negara tersebut:

a. Memilik catatan yang buruk terkait pelaksanaan hak asasi manusia;

b. Memiliki catatan yang buruk terhadap pengelolaan lingkungan hidup;

c. Memiliki catatan yang terhadap perlakuan terhadap tenaga kerja;

d. Memiliki catatan yang buruk terhadap penanganan tindakan teroris;

e. Memiliki catatan yang buruk dimana negara tersebut tidak melaksanakan putusan arbitrase internasional yang memenangkan negara pemberi GSP;

Melakukan atau terlibat dalam tindakan kartel antara negara, seperti negara-negara pengekspor minyak bumi (Organization of the Petroleum Exporting Countries/OPEC).

Kriteria-kriteria tersebut di atas sepenuhnya pertimbangan subyektif suatu negara.

c) AmbangBatas NilaidanPemberhentian Sementara DFQF

Adanya pembatasan ini juga diberlakukan di negara lain. Di Thailand misalnya, penerapan tarif preferensi terhadap produk ekspor dari LDCs dapat ditangguhkan sementara maupun permanen, jika terdapat penipuan atau penyimpangan dari prosedur maupun peraturan terkait keterangan asal produk. Selain itu, jika perlakuan tarif preferensi menyebabkan produk yang diimpor dari LDCs melonjak tinggi sehingga menyebabkan kerugian maupun ancaman kerugian terhadap produk serupa dalam negeri, maka penerapan tarif preferensi ditangguhkan dan tarif normal untuk produk tersebut akan diberlakukan kembali.

Sementara itu, Pemerintah India menerapkan preferential safeguard measure apabila terjadi peningkatan jumlah impor dari LDCs baik secara absolut ataupun secara relatif yang menyebabkan serious injury pada produksi dalam negeri India. Mekanisme ini akan dilakukan dengan pemberitahuan terlebih dahulu kepada negara penerima 
apabila India akan menerapkan safeguard duty, kecuali untuk keadaan yang mendesak dan produk pertanian. Selain itu, Pemerintah India juga mengatur tentang mekanisme pemberhentian skema DFTP kepada LDCs, jika antara lain terdapat bukti-bukti yang menunjukkan terjadinya pelanggaran seperti penipuan dan pelanggaran lain, impor melebihi batas produksi yang bisa dilakukan dan kapasitas ekspor dari negara penerima, dan negara penerima telah lulus dari kriteria LDC dengan mengacu pada kriteria yang dikembangkan Pemerintah India. ${ }^{34}$

Dalam skema GSP, terdapat beberapa cara yang bisa digunakan untuk membatasi GSP, antara lain: import ceilings, valueadded requirements, exclusions for importsensitive industries, dan competitive need limits (CNL). Sebagai suatu perbandingan, Amerika Serikat mengunakan CNL. CNL merupakan istilah yang khusus digunakan dalam kaitannya dengan pemberlakuan duty free dalam Generalized System of Preferences (GSP) Amerika Serikat. Dalam skema CNL, jika impor barang tersebut melewati ambang batas nilai impor (dalam dolar) atau pangsa impor (dalam persen), maka perlakuan GSP duty free akan ditiadakan dan barang tersebut kembali dikenai tarif normal (normal trade relations). Pada tahun 2010, ambang batas nilai impor adalah USD145 juta untuk suatu produk atau $50 \%$ dari total impor produk tersebut. Ambang batas nilai impor akan disesuaikan dengan tingkat pertumbuhan PDB (Pendapatan Domestik Bruto) tiap tahunnya. ${ }^{35}$

Skema CNL dimungkinkan untuk dikecualikan, namun pengabaian $\mathrm{CNL}$ akan dicabut selama lima tahun jika impor melebihi 1,5 kali ambang batas nilai dolar atau share $>75 \%$ dari total impor Amerika
Serikat. Total waivers untuk CNL tidak boleh melebihi $30 \%$ total GSP duty-free. Secara khusus, skema CNL dimungkinkan untuk dikecualikan:

a. Jika produk tersebut tidak diproduksi di dalam negeri, maka ambang 50\%-dan bukan ambang nilai dolar-bisa diabaikan,

b. Jika produk tersebut bersifat de minimis, yaitu total nilai impor $<\$ 19$ juta (tahun 2008), maka ambang 50\%-dan bukan ambang nilai dolar-bisa diabaikan,

c. Untuk negara yang masuk kategori least developed countries sebagaimana yang ditetapkan oleh presiden atau negara-negara Sub-Sahara,

d. Untuk negara yang mempunyai hubungan historis khusus perdagangan dengan Amerika Serikat (saat ini hanya Filipina yang memenuhi syarat ini).

e. Secara umum, skema CNL dimungkinkan untuk dikecualikan jika, pertama, presiden mendapat masukan mengenai dampak negatif pada industri domestik, dan kedua, ada kepentingan ekonomi nasional sebagaimana termaktub dalam Trade Act tahun 1974 bagian 501 dan $502(\mathrm{c}){ }^{36}$

\section{d) Jangka Waktu DFQF \\ Indonesia juga dapat menentukan batas} waktu pemberian DFQF, dalam arti, bahwa pemberian DFQF tidak bersifat selamanya, tapi sementara (temporary). Thailand misalnya, memberlakukan tarif preferensi sejak 9 April 2015 hingga 31 Desember 2020.

\section{Kesimpulan}

Sebagai negara yang telah meratifikasi perjanjian pendirian WTO, maka sikap Indonesia 
adalah haruslah mengikuti perjanjian-perjanjian dalam kerangka perjanjian WTO, termasuk perjanjian DFQF sebagaimana tersebut di atas. Mencermati putusan Hongkong Ministrial Decision tampak bahwa DFQF bersifat wajib untuk negara-negara maju dan bersifat anjuran bagi negara berkembang. Indonesia sebagai negara berkembang, meskipun bersifat anjuran, namun apabila dicermati perkembangan DFQF di negara lain, misalnya Thailand, India, dan Tiongkok, maka DFQF bagi Indonesia juga patut untuk diterapkan mengingat semangatnya adalah untuk membantu negara kurang berkembang.

Dalam pemberian preferensi DFQF ini, Indonesia sebaiknya mengunakan skema atau pola seperti GSP, mengingat tidak adanya pengaturan yang jelas terkait dengan DFQF. Penerapan DFQF haruslah sejalan dengan ketentuan Pasal 87 Ayat (1) dan (2) Undang-Undang Nomor 7 Tahun 2014 tentang Perdagangan, yang menyatakan Pemerintah dapat memberikan preferensi Perdagangan secara unilateral kepada negara kurang berkembang dengan tetap mengutamakan kepentingan nasional. Frasa "mengutamakan kepentingan nasional" diwujudkan dengan membuat persyaratan-persyarataan yang harus diikuti dengan negara LDCs apabila mereka berkeinginan untuk memperoleh preferensi DFQF seperti suatu negara berkeinginan memperoleh GSP. Persyaratan yang dibuat tersebut antara lain dapat berkaitan dengan terkait produk DFQF, kriteria negara penerima DFQF, batasan nilai DFQF dan pemberhentian sementara, serta jangka waktu pemberian preferensi DFQF.

\section{DAFTAR PUSTAKA}

\section{A. Buku}

Adolf, Huala, 2005, Hukum Perdagangan Internasional, Raja Grafindo Persada, Jakarta.

KPI, Puska ,2015, Laporan Akhir Analisis Usulan Pemberian Fasilitas Bebas Bea dan Bebas Kuota Bagi Negara Least Developed Countries, Kemenenterian Perdagangan Republik Indonesia.

Pryles, Michael, et. al., 2004, International Trade Law-Commentary and Materials, Thomson Reuter Legal.

Sutrisno, Nandang, 2012, Pemajuan Kepenetingan Negara-negara Berkembang Dalam Sistem WTO: Studi Mekanisme Perlakuan Khusus dan Berbeda Dengan Referensi Khusus Terhadap Indonesia, The Institute for Migrant Rights Press, Cianjur.

Syahmin AK, 2006, Hukum Dagang Internasional, Raja Grafindo Persada, Jakarta.

Widodo, Tri, et.al., 2015, Analisis Rekomendasi Daftar Produk pemberian fasilitas Duty Free Quota Free (DFQF) bagi Produk Ekspor
Negara Least Development Countries (LDCs), P2EB (Penelitian dan Pelatihan Ekonomi dan Bisnis, Fakultas Ekonomi, Universitas Gadjah Mada, Yogyakarta.

Van Den Bossche, Peter, 2005, The Law and Policy of the World Trade Organization-Text, Cases and Materials, Cambrige University Press.

"Handbook on Duty-Free Quata-Free and Rules Origin”, United Nations Conference on Trade and Development.

\section{B. Artikel Jurnal}

Beynon, Paul, "Community Mutual Recognition Mutual Agreements, Technical Barriers to Trade, And the WTO Most Favoured Nation Principles", E.L.Rev. 2003, 28 (2), 231-249.

\section{Makalah/Pidato}

Hawin, M., Focus Group Discussion, "Analisis Rekomendasi Daftar Produk pemberian fasilitas Duty Free Quota Free (DFQF) bagi Produk Ekspor Negara Least Development Countries (LDCs), di Fakultas Ekonomi, Universitas Gadjah Mada, pada tanggal 5 
November 2015.

Herjanto, Eddy (Kepala Puslitbang Standarisasi BSN), "Standarisasi: Peran Dan Perkembangannya Dalam Memfasilitasi Perdagangan Di Indonesia", 7 Mei 2008.

\section{Internet}

DJPEN, "Definisi dan Manfaat", http://djpen. kemendag.go.id/app_frontend/contents/147definisi-manfaat, diakses 3 Agustus 2018.

Sekretariat BSN, "Konferensi Tingkat Menteri Ke 9 WTO, Bali Nusa Dua Convention Centre, 3-6 Desember 2013", http://bsn.go.id/ main/berita/detail/4935/konferensi-tingkatmenteri-ke-9-wto-bali-nusa-dua-conventioncentre-3-6-desember-2013\#.XRyBU_5S_IU, diakses 3 Juli 2019.

WTO, "Members and Observers", http://www.wto. org/english/thewto_e/whatis_eltif_elorg6_e. htmm, diakses 14 Juli 2017.

SwaOnline, "Indonesia Pertimbangkan DFQF untuk
Negara Kurang Berkembang", https://swa. co.id/swa/trends/management/indonesiapertimbangkan-dfqf-untuk-negara-kurangberkembang, diakses 3 Juli 2017.

WTO, "Ministerial Declaration: Annexes Adopted on 18 December 2005, Decision on Measures in Favour of Least-Developed Countries", https://www.wto.org/english/thewto_e/ minist_e/min05_e/final_annex_e.htm, pada 3 Juli 2017.

WTO, "Preferential Tariff Treatment For leastDeveloped Countries decision On Waive radopted On 15 June 1999", https://www.wto. org/english/docs_ellegal_e/waiver1999_e. $p d f$, diakses 3 Juli 2017.

WTO, "Ministerial Conference ninth Session Bali, 3-6 December 2013 on Duty-Free And Quota-Free Market Access For LeastDeveloped Countries", https://www.wto.org/ english/thewto_e/minist_e/mc9_e/bali_texts_ combined_e.pdf, diakses 3 Juli 2019. 